\title{
Role of mesothelial cells in peritoneal antibacterial defence
}

\author{
M A Muijsken, H J C M Heezius, J Verhoef, H A Verbrugh
}

\begin{abstract}
Whether phagocytosis of Staphylococcus aureus by polymorphonuclear neutrophils, monocytes, and peritoneal macrophages takes place when the staphylococci are adherent to monolayers of human mesothelial cells in the absence of opsonins was investigated. Adherence of $S$ aureus to mesothelial monolayers increased significantly when the bacteria were opsonised with pooled human serum, but phagocytosis by polymorphonuclear neutrophils and monocytes occurred independently. Phagocytosis by peritoneal macrophages, however, was only marginal. Pretreatment of polymorphonuclear neutrophils with inhibitors of cellular metabolism and motility reduced their phagocytic capacity.

These results indicate that the surface of mesothelial cells provides favourable conditions for the elimination of staphylococci in the peritoneal cavity. Phagocytic motility seems to be important in surface phagocytosis. The inability of peritoneal macrophages to phagocytise staphylococci adherent to the mesothelial cells suggests that they contribute little to the antibacterial defence of the peritoneal membrane of patients receiving peritoneal dialysis.
\end{abstract}

Peritoneal dialysis is an accepted form of treatment for patients with end-stage renal disease. A major drawback of this treatment is the high incidence of peritonitis which causes considerable morbidity in patients receiving continuous peritoneal dialysis (CPD), resulting in a high drop-out rate. ${ }^{12}$ The use of a permanent indwelling catheter facilitates the entrance of micro-organisms to the peritoneal cavity. Adherence of bacteria to cellular surfaces is often the first step in colonisation and subsequent infection. Staphylococci are the predominant causal agents of peritonitis in this setting. ${ }^{2-5}$ Little is known about the role of mesothelial cells in the pathogenesis of peritonitis. In this study we investigated whether mesothelial cells support surface phagocytosis of staphylococci by human polymorphonuclear neutrophils, monocytes, and peritoneal macrophages.

\section{Methods}

Human mesothelial cells were isolated from omental tissue from patients undergoing abdominal surgery for a non-infectious cause, using methods previously described by van Bronswijk et al. ${ }^{6}$ Informed consent was obtained from each of the donors. Briefly, the tissue was immediately put in Medium M199 (Gibco Europe, Breda, Holland) and kept at $37^{\circ} \mathrm{C}$ until further processing. The tissue was cut into $5 \times 5 \mathrm{~cm}$ pieces, washed in phosphate buffered saline (PBS), and subsequently incubated in an overhead rotator with trypsin/ EDTA $(0.05 / 0.02 \%$, Gibco Europe, Breda, Holland) for 30 minutes at $37^{\circ} \mathrm{C}$. Mesothelial cells were harvested by centrifugation at $160 \times$ $g$ for 10 minutes. The cell pellet was washed in Medium M199, the cells were counted, and seeded into polystyrene tissue culture flasks coated with fibronectin ${ }^{7}$ (No. 3075, Costar, Cambridge, Massachusetts, USA) at a concentration of $10^{6}$ cells/flask.

The cells were cultured in M199 supplemented with HEPES $(1 \cdot 2 \mathrm{~g} / 1)$, sodium-bicarbonate $(2 \mathrm{~g} / \mathrm{l})$, heat-inactivated, new born calf serum (10\%, Integro, Zaandam, Holland), $2 \mathrm{mmol} / 1$ L-glutamine, gentamicin $(10 \mu \mathrm{g} / \mathrm{ml})$, and vancomycin $(25 \mu \mathrm{g} / \mathrm{ml})$; "complete M199". The cells were grown in monolayer culture at $37^{\circ} \mathrm{C}$ in a fully humidified $95 \%$ air $-5 \%$ carbon dioxide atmosphere. At confluency the monolayer was washed with PBS and incubated with trypsin/EDTA for 45 seconds. After all the cells had detached from the tissue culture flask the trypsin-EDTA was diluted 1 in 10 with "complete M199". The cells were either reseeded into two new tissue culture flasks or were subcultured in 96-well flat bottom microtitre plates (Nunclon, Denmark) for further experiments $\left(2 \times 10^{4}\right.$ cells/well $)$. The identity of mesothelial cells was regularly checked by cell morphology, growth pattern characteristics, and immunofluorescence staining for presence of cytokeratins and absence of factor VIII related surface antigen using monoclonal antibodies (Dakopatts, Glostrup, Denmark). ${ }^{8}$

\section{BACTERIA}

Staphylococcus aureus Cowan I (protein A rich), $S$ aureus $\mathrm{H}$ (teichoic acid rich), and its teichoic acid deficient mutant $\mathrm{H} 52 \mathrm{~A} 5$ were used. ${ }^{9}$ For some experiments $S$ aureus Cowan I was pretreated with pronase $(1 \mathrm{mg} / \mathrm{ml} ; \mathrm{E}$ Merck AG, Darmstadt, Germany) for 30 minutes at $37^{\circ} \mathrm{C}$ to remove surface proteins. 9

For radiolabelling, bacteria were inoculated in Mueller-Hinton broth (Difco Laboratories, Detroit, Michigan, USA) containing $0.74 \mathrm{MBq}$ ${ }^{3} \mathrm{H}$-adenine (specific activity $888 \mathrm{MBq} / \mathrm{mol}$ ) 
(Amersham International, UK). ${ }^{10}$ After 18 hours of growth at $37^{\circ} \mathrm{C}$ bacteria were washed three times in PBS. A concentration of $5 \times 10^{8}$ $\mathrm{CFU} / \mathrm{ml}$ was then obtained using a photometric method that had been standardised by a pour plate method (Lange photometer, Berlin, Germany). ${ }^{11}$

\section{OPSONISATION PROCEDURE}

Sera from 10 healthy donors were pooled and stored at $-70^{\circ} \mathrm{C}$ in small aliquots. Before use pooled human serum was thawed and diluted in "complete M199" without antibiotics and without newborn calf serum. Bacteria $(2.5 \times$ $10^{8} \mathrm{CFU} / \mathrm{ml}$ ) were incubated with $5 \%$ pooled human serum in $\mathrm{M} 199$ at $37^{\circ} \mathrm{C}$ in a waterbath under constant shaking (150 rpm) for 30 minutes (Marius Instruments, Utrecht, The Netherlands). After centrifugation (15 minutes, $3000 \mathrm{rpm}, 4^{\circ} \mathrm{C}$ ), opsonised bacteria were resuspended in M199 at a concentration of $1 \times 10^{8} \mathrm{CFU} / \mathrm{ml}$ and kept at $4^{\circ} \mathrm{C}$ until use. Unopsonised bacteria were processed in the absence of serum but otherwise in the same way.

\section{LEUCOCYTES}

Polymorphonuclear neutrophils and monocytes were isolated from anticoagulated venous blood from healthy donors by dextran sedimentation of erythrocytes and differential density centrifugation on Ficoll-Isopaque gradient using a method modified from Böyum $^{12}$ as previously described. ${ }^{13}$ Both polymorphonuclear neutrophils and mononuclear cell preparations were washed once in M199 without antibiotics, resuspended, and total cell counts were performed. The mononuclear cell fraction was also differentially counted. The final leucocyte pellets were adjusted to a concentration of $1 \times 10^{7}$ polymorphonuclear neutrophils or monocytes per ml. For control experiments killed polymorphonuclear neutrophils were used. Polymorphonuclear neutrophils were preincubated with $2 \%$ paraformaldehyde at room temperature for 30 minutes. After incubation cells were washed three times in M199. Peritoneal cells were isolated from peritoneal dialysis effluents from uninfected patients undergoing continuous peritoneal dialysis, as described previously. ${ }^{14}$ Briefly, cells were sedimented by centrifugation and collected in Hanks's balanced salt solution containing $0 \cdot 1 \%$ gelatin (GHBSS). Cells were then washed once in M199. Total and differential cell counts were performed. The final cell suspensions were adjusted to contain $1 \times 10^{7}$ peritoneal macrophages/ml of M199.

TREATMENT OF LEUCOCYTES WITH PRONASE, CYTOCHALASIN B, AND 2-DEOXY-D-GLUCOSE To determine the nature of the interaction between polymorphonuclear neutrophils and bacteria, polymorphonuclear neutrophils were treated with pronase, cytochalasin $\mathrm{B}$, or 2deoxy-D-glucose (2d-glu). For pronase treatment, polymorphonuclear neutrophils $(5 \times$ $10^{6} / \mathrm{ml}$ ) were incubated with $1 \mathrm{mg}$ pronase (pronase E, 70000 PUK; Merck) per $\mathrm{ml}$ in $\mathrm{Ca}^{+}$and $\mathrm{Mg} 2^{+}$free G-HBSS for 30 minutes at $37^{\circ} \mathrm{C}$. The cells were then washed and suspended in M199. For cytochalasin B or 2dglu treatment, polymorphonuclear neutrophils were resuspended in M199 containing $5 \mu \mathrm{g}$ of cytochalasin B (Aldrich Chemical Co, Inc, Milwaukee, Wisconsin, USA) per $\mathrm{ml}$ or $50 \mathrm{mM}$ 2d-glu (Serva, Heidelberg, Germany) and incubated for 10 minutes at $37^{\circ} \mathrm{C}$ before use in the phagocytosis assay. As a control, polymorphonuclear neutrophils were also preincubated with $50 \mathrm{mM}$ glucose. During the assay, cytochalasin B, 2d-glu, and glucose were not removed from the medium.

\section{SURFACE PHAGOCYTOSIS ASSAY}

Surface phagocytosis assays were performed using a slightly modified version of a previously described method. ${ }^{15}$ Confluent monolayers of mesothelial cells in 96-well tissue culture plates were washed once with "complete M199" without antibiotics. Subsequently, radiolabelled bacteria $(50 \mu \mathrm{l})$ were added to the wells. The tissue culture plates were then incubated for 60 minutes at $37^{\circ} \mathrm{C}, 5 \%$ carbon dioxide, to allow the bacteria to attach to the monolayer. The wells were then carefully washed twice to remove only the non-adherent bacteria without damage to the monolayer. Subsequently, phagocytes $\left(100 \mu \mathrm{l}\right.$ of $5 \times 10^{6} /$ $\mathrm{ml})$ were added to the wells. After incubation for 60 minutes at $37^{\circ} \mathrm{C}, 5 \%$ carbon dioxide, icecold PBS was added to the wells to stop the interaction between phagocytes and bacteria; for determination of adherence, two control wells without phagocytes were used during this incubation period. In some experiments other time intervals were evaluated to study the kinetics of uptake. The content of the well was thoroughly mixed and transported to a polypropylene biophial (Biovial, Beckmann Instruments, Chicago, Illinois, USA). The wells were then rinsed with $3 \mathrm{mM}$ EDTA in PBS until all cells were removed from the wells. These rinses were added to the respective biophial. Complete removal of cells from the wells was checked microscopically. For determination of adherence $2.5 \mathrm{ml}$ of scintillation liquid (Safe Fluor S, Hicol, Oud-Beijerland, The Netherlands) was immediately added to the respective phials.

The content of the other biophials was washed twice with ice-cold PBS (1200 rpm, 10 minutes, $\left.4^{\circ} \mathrm{C}\right)$. Then lysostaphin $(1 \mathrm{U} / \mathrm{ml})$ was added to the phials and incubated at $4^{\circ} \mathrm{C}$ for 15 minutes. After lysostaphin treatment two more washing cycles were performed. After washing, $2.5 \mathrm{ml}$ scintillation liquid was added and the radioactivity counted in a liquid scintillation counter (PW 4700, Philips, Almelo, the Netherlands). Each test was performed in duplicate. Adherence of staphylococci was expressed as the percentage of remaining radioactivity compared with the total counts of radiolabelled bacteria added to the well. Phagocytosis was expressed as percentage of remaining radioactivity compared with radioactivity corresponding to adhered bacteria. In some experiments M199 without 
phagocytes was added to the well after the adherence step to evaluate the level of mesothelial cell associated radioactivity after a certain time ( 60 minutes).

Results were expressed as the mean (SEM) of three or more experiments. Significance was assessed using Student's $t$ test. P values smaller or equal to 0.05 were regarded as significant.

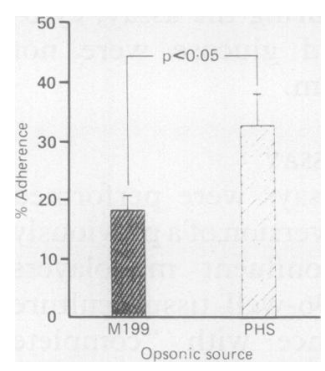

Figure 1 Adherence of $S$ aureus Cowan I to monolayers of human mesothelial cells. Bacteria were preopsonised with 5\% pooled human serum (PHS) or with Medium 199 (M199). Bars and brackets indicate the means (SEM) of at least 11 separate experiments.

Figure 2 Kinetics of phagocytosis of $S$ aureus Cowan I adherent to mesothelial monolayers by polymorphonuclear neutrophils. Bacteria were preopsonised with 5\% PHS or with M199. Control experiments were performed with polymorphonuclear polymorphonuclear paraformaldehyde. Experiments performed without

polymorphonuclear neutrophils gave similar results (data not shown in figure). Data are means (SEM) of at least three separate experiments.

\section{Results}

The results of experiments on the adherence of $S$ aureus Cowan I to mesothelial cell monolayers are shown in fig $1 . S$ aureus adhered well to these monolayers, even in the absence of serum proteins, but preopsonised bacteria adhered significantly better to mesothelial cell monolayers compared with unopsonised bacteria $(32.7(5.3) \%$ v $18.3(2.5) \%)(\mathrm{p}<0.05)$.

The rate of phagocytosis by polymorphonuclear neutrophils is shown in fig 2. During the first 15 minutes most adherent bacteria were taken up by the polymorphonuclear neutrophils. Preopsonisation with 5\% pooled human serum did not influence the rate of phagocytosis. After 60 minutes of incubation a plateau in the level of uptake was reached. In control experiments using polymorphonuclear neutrophils killed by paraformaldehyde and in experiments performed in the absence of polymorphonuclear neutrophils the remaining radioactivity in the well after 60 minutes was comparable with the retrieved activity after zero minutes phagocytosis with live polymorphonuclear neutrophils (fig 2). To exclude the possibility that adherence of bacteria to mesothelial cells or to polymorphonuclear neutrophils could be measured as phagocytosis in the phagocytosis assay, lysostaphin was used at the end of each experiment. Lysostaphin has been shown to lyse more than $90 \%$ of the extracellular staphylococci. ${ }^{11}$ Phagocytosis by peritoneal macrophages was significantly less than that of donor polymorphonuclear neutrophils or monocytes (table 1).

The influence of two major cell wall components on the uptake by polymorphonuclear neutrophils of $S$ aureus adherent to mesothelial monolayers was studied using $S$ aureus Cowan $\mathrm{I}$, which is rich in protein $\mathrm{A}$, and $S$ aureus $\mathrm{H}$, which has a high teichoic acid content. To

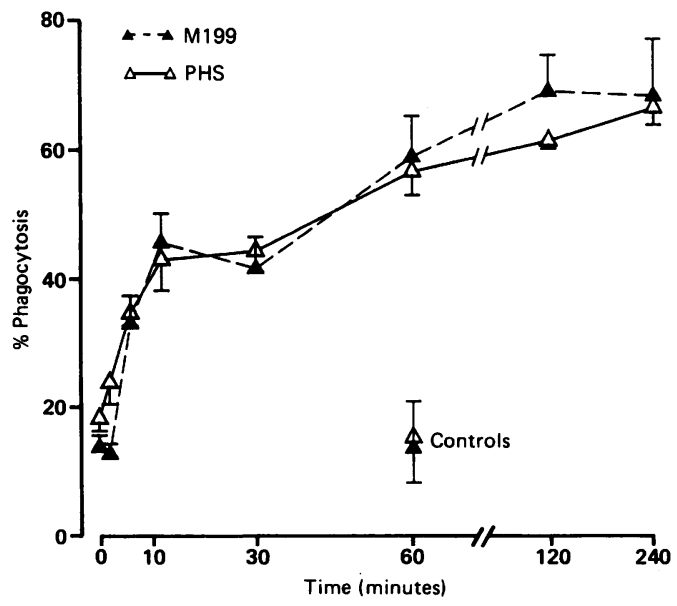

Table 1 Percentage phagocytosis of $S$ aureus adherent to mesothelial monolayers by phagocytes from different origin

\begin{tabular}{lll}
\hline & \multicolumn{2}{l}{ Opsonic source } \\
\cline { 2 - 3 } Phagocytes & M199 $\quad P H S$ & \\
\hline
\end{tabular}

\section{Polymorphonuclear}

neutrophils

$55 \cdot 8(4 \cdot 4)$

$61 \cdot 0(3 \cdot 4)$

$\begin{array}{lll}\text { Monocytes } & 52 \cdot 8(5.0) & 56.0(6.5) \\ \text { Peritoneal } & 30.1(6.6)^{\star} & 32.5(5.8)^{\star}\end{array}$

$\begin{array}{lll}\text { Peritoneal macrophages } & 30 \cdot 1(6 \cdot 6)^{\star} & 32 \cdot 5(5 \cdot 8)^{\star} \\ \text { No phagocytes } & 29 \cdot 0(3 \cdot 6)^{\star} & 33 \cdot 4(3 \cdot 3)^{\star}\end{array}$

${ }^{\star} p<0,05$ compared with percentage uptake by polymorphonuclear neutrophils or monocytes.

Data are means (SEM) of at least nine separate experiments for polymorphonuclear neutrophils and monocytes and for control experiments without phagocytes. Peritoneal macrophages from four patients were tested in one to 11 separate experiments per patient.

remove the cell wall associated protein A $S$ aureus Cowan I was pretreated with pronase. We also used $S$ aureus 52A5, a teichoic acid deficient mutant of $S$ aureus $\mathrm{H}$. Phagocytosis of staphylococci was independent of proteins, including protein $\mathrm{A}$, in their cell walls (table 2); the pronase-treated $S$ aureus Cowan I was phagocytised as well as the untreated strain. The presence or absence of cell wall teichoic acid did not influence the rate of phagocytosis.

To study the interaction between polymorphonuclear neutrophils and bacteria, polymorphonuclear neutrophils were treated with various inhibitors (table 3 ). To examine whether the binding of the adherent $S$ aureus to polymorphonuclear neutrophils was mediated via a pronase-sensitive receptor, polymorphonuclear neutrophils were pretreated with pronase. Pronase inactivates protein receptors, such as the $\mathrm{C} 3 \mathrm{~b}$ receptor in the membrane of the polymorphonuclear neutrophils. ${ }^{16}$ Pronase treatment of the polymorphonuclear neutrophils significantly reduced their ability to ingest both opsonised and unopsonised $S$ aureus Cowan I; phagocytosis was reduced by 68 and $69 \%$, respectively (table 3 ). Cytochalasin B treatment of polymorphonuclear neutrophils also reduced the uptake of opsonised and unopsonised bacteria, with 46 and $37 \%$, respectively. 2D-glu treatment of polymorphonuclear neutrophils reduced uptake to $39 \%$ for opsonised bacteria and to $30 \%$ for unopsonised bacteria compared with untreated polymorphonuclear neutrophils. Preincubation of polymorphonuclear neutrophils with glucose had no effect.

\section{Discussion}

This study was done to elucidate further the role of mesothelial cells in the pathogenesis of peritonitis associated with chronic peritoneal dialysis (CPD). Mesothelial cells form the inner surface of the peritoneal cavity. In vitro cultured monolayers of human mesothelial cells support phagocytosis of $S$ aureus adherent to the surface. The uptake of bacteria occurred rapidly and occurred independently of the presence of serum opsonins. This contrasts with phagocytosis of staphylococci by polymorphonuclear neutrophils or monocytes in suspension, where serum opsonins are essential for phagocytosis to occur. ${ }^{1718}$ Both polymorphonuclear neutrophils and monocytes 
Table 2 Percentage phagocytosis by polymorphonuclear neutrophils of $S$ aureus strains with different cell wall characteristics adherent to mesothelial cell monolayers

\begin{tabular}{llll}
\hline & & \multicolumn{2}{l}{ Opsonic source } \\
\cline { 3 - 4 } S aureus strain & Cell wall characteristic & $M 199$ & PHS \\
\hline Cowan I & Protein A rich & $73 \cdot 6(6 \cdot 4)$ & $67 \cdot 8(6 \cdot 0)$ \\
Cowan I & Pronase treated & $71 \cdot 2(3 \cdot 4)$ & $70 \cdot 1(8 \cdot 9)$ \\
H & Teichoic acid rich & $70 \cdot 0(4 \cdot 7)$ & $62 \cdot 7(4 \cdot 6)$ \\
H52A5 & Teichoic acid deficient & $77 \cdot 1(4 \cdot 1)$ & $71 \cdot 8(3 \cdot 9)$ \\
\hline
\end{tabular}

Data are means (SEM) of at least three separate experiments.

phagocytised well, in contrast to peritoneal macrophages, isolated from the effluents of patients who were maintained on continuous peritoneal dialysis.

Adherence of $S$ aureus and $S$ epidermidis to mesothelial cells was described recently. ${ }^{19} \mathrm{We}$ used $S$ aureus, which was shown to adhere much better to mesothelial monolayers than $S$ epidermidis. ${ }^{19}$ Preopsonisation of $S$ aureus with pooled human serum increased adherence significantly.

The positive role of a cell surface in the process of phagocytosis of unopsonised bacteria has been described previously in a model where monolayers of in vitro cultured human endothelial cells were used. ${ }^{20}$ Uptake of unopsonised staphylococci on an endothelial surface by polymorphonuclear neutrophils is only partly dependent on intact locomotion of the phagocyte. ${ }^{20}$ To determine whether intact cellular movement was important in the uptake of staphylococci from mesothelial cell surface by phagocytes, polymorphonuclear neutrophils were pretreated with $2 \mathrm{~d}$-glu and cytochalasin B. 2D-glu inhibits glycolysis and hexose-monophosphate shunt and therefore reduces intracellular adenosine triphosphate activity. ${ }^{21}$ Treatment of polymorphonuclear neutrophils with $2 \mathrm{~d}$-glu resulted in a reduction of phagocytosis of both opsonised and unopsonised $S$ aureus $\mathrm{CI}$ by $40 \%$. The effect of $2 \mathrm{~d}-$ glu was not due to competition with glucose residues for lectin-like receptors ${ }^{22}$ as treatment of the polymorphonuclear neutrophils with 50 $\mathrm{mM}$ glucose had no effect. The effect of $2 \mathrm{~d}$-glu was comparable with that of cytochalasin B, a metabolite from the mould Helmintosporium dematioideum which interferes with the function of cytoplasmic microfilaments. ${ }^{23} 2 \mathrm{D}$-glu and cytochalasin B may act on the process of surface phagocytosis by the same mechanisminhibition of normal cellular movement of the phagocyte.

Peritoneal macrophages form an important first line of defence in the peritoneal cavity. Peritoneal macrophages from peritoneal

Table 3 Effect of pretreatment of polymorphonuclear neutrophils with various cell function inhibitors on percentage phagocytosis of $S$ aureus Cowan I adherent to mesothelial monolayers

\begin{tabular}{llll}
\hline & \multicolumn{3}{l}{ Opsonic source } \\
\cline { 2 - 4 } Pretreatment of polymorphonuclear neutrophils & M199 & PHS & p Value \\
\hline Untreated & $52 \cdot 7(5 \cdot 5)$ & $51 \cdot 4(3 \cdot 6)$ & \\
Glucose & $47 \cdot 1(4 \cdot 7)$ & $46 \cdot 1(3 \cdot 2)$ & NS \\
2deoxy-D-glucose & $36 \cdot 9(5 \cdot 1)$ & $31 \cdot 1(5 \cdot 3)$ & $<0.02$ \\
Cytochalasin B & $33 \cdot 3(5 \cdot 5)$ & $27 \cdot 6(3.9)$ & $<0.05$ \\
Pronase & $16 \cdot 5(4 \cdot 0)$ & $16 \cdot 4(3 \cdot 4)$ & $<0.001$ \\
\hline
\end{tabular}

Data are expressed as means (SEM) of six separate experiments. effluents did not take up staphylococci from the mesothelial monolayer, but peritoneal macrophages do phagocytise bacteria in a suspension assay, where bacteria are presented to the phagocyte under vigorous shaking conditions. ${ }^{14}$ These results suggest that the cellular movement of peritoneal macrophages may be defective.

To examine the possibility that attachment and ingestion of staphylococci are mediated via a protein receptor on the cell surface of the polymorphonuclear neutrophils, the polymorphonuclear neutrophils were treated with pronase. Pronase treatment of the polymorphonuclear neutrophils reduced the phagocytic capacity by $69 \%$ compared with untreated polymorphonuclear neutrophils $(p<0.001)$. The reduction was independent of the presence of pooled human serum. This indicates that a pronase sensitive structure is involved in the uptake of $S$ aureus by the polymorphonuclear neutrophils on the mesothelial surface. In contrast, pronase treatment of polymorphonuclear neutrophils did not influence phagocytosis of unopsonised staphylococci on an endothelial surface. ${ }^{20}$

These in vitro findings suggest that peritoneal macrophages may only partially contribute to the defence of the peritoneal membrane. During the initial stages of peritonitis valuable time may be lost when the microorganisms multiply freely before the arrival of phagocytes and opsonins from the circulation. We have shown that phagocytosis of staphylococci adherent to the mesothelial cell surface by peripheral blood phagocytes can proceed in the absence of opsonins. It is also known that peritoneal macrophages can phagocytise nonadherent staphylococci in suspension where their motility is not mandatory. ${ }^{14}$ Therefore, it seems very important to investigate the reasons for the lack of motility of peritoneal macrophages. Because phagocytosis of staphylococci in suspension depends on the presence of opsonins, however, only a few bacteria might be phagocytised by peritoneal macrophages under these conditions.

The observation that incubation of mesothelial cells with radiolabelled bacteria in the absence of polymorphonuclear neutrophils resulted in a considerable amount of lysostaphinresistant mesothelial cell-associated radioactivity raises the question as to whether mesothelial cells themselves can phagocytise bacteria. Whether this is the case and what the implications of such an event would be for the pathogenic mechanism of peritonitis and antibiotic treatment is currently under study.

The assistance of $R$ P Verkooyen in making the graphs is gratefully acknowledged. This study was supported by grant C88.0743 of the Kidney Foundation of The Netherlands.

1 Fenton SAA. Peritonitis related death among CAPD patients. Peritoneal Dial Bull 1983;3:S9-11.

2 Nolph KD, Cutler SJ, Steinberg SM, Novak JW. Continuous ambulatory peritoneal dialysis in the United States: uous ambulatory peritoneal dialysis in the United

3 Swartz RD. Chronic peritoneal dialysis: Mechanical and infectious complications. Nephron 1985;40:29-37.

infectious complications. Nephron 1985;40:29-37.
Boeschoten EW. Continuous ambulatory peritoneal dialysis: Boeschoten EW. Continuous ambulatory peritoneal dialysis:
$A$ clinical study of various aspects of CAPD. Rhodopi, Amsterdam: 1988, Thesis.

5 Vas SI. Peritonitis. In: Nolph KD, ed. Peritoneal dialysis. 
2nd edn. Boston: Martinus Nijhoff, 1985:403-39

6 Van Bronswijk H, Verbrugh HA, Bos HJ, et al. Cytotoxic effects of commercial continuous ambulatory peritoneal dialysis (CAPD) fluids and of bacterial exoproducts on human mesothelial cells in vitro. Peritoneal Dial Intern 1989;9:197-202.

7 Reinders JH, de Groot PG, Gonsalves MD, Zandbergen J, Loesberg C, van Mourik JA. Isolation of a storage and secretory organelle containing von Willebrand protein secretory organelle containing von Willebrand protein
from cultured human endothelial cells. Biochim Biophys from cultured human

8 Wu Y-J, Parker LM, Binder NE, et al. The mesothelial keratins: a new family of cytoskeletal proteins identified in cultured mesothelial cells and nonkeratinizing epithelia. Cell 1982;31:693-703.

9 Spika JS, Verbrugh HA, Verhoef J. Protein A effect on alternative pathway complement activation and opsonization of Staphylococcus aureus. Infect Immun 1981;34: 455-60.

10 Verbrugh HA, Peterson PK, Nguyen BT, Sisson SP, Kim Y. Opsonization of encapsulated Staphylococcus aureus: The role of specific antibody and complement. J Immunol 1982;129:1681-87.

11 Verhoef J, Peterson PK, Quie PG. Kinetics of staphylococcal opsonization, attachment, ingestion and killing by
human polymorphonuclear leucocytes: a quantative assay human polymorphonuclear leucocytes: a quantative assay
using ${ }^{3} \mathrm{H}$-thymidine labelled bacteria. $J$ Immunol Methods using ${ }^{3} \mathrm{H}$-thymidin

12 Böyum A. Isolation of mononuclear cells and granulocytes from human blood. Scand J Clin Lab Invest 1968;97: S77-S89.

13 Verbrugh HA, Peters R, Peterson PK, Verhoef J. Phagocytosis and killing of staphylococci by human polymorphonuclear and mononuclear leukocytes. J Clin Pathol 1978;31:539-45.

14 Verbrugh HA, Keane WF, Hoidal JR, Freiberg MR Elliot GR, Peterson PK. Peritoneal macrophages and opsonins: antibacterial detense in patients undergoing chronic peritoneal dialysis. J Infect Dis 1983;147:1018-29.

15 VandenBroucke-Grauls CMJE, Thijssen HVWM, Verhoef J. Interaction between human polymorphonuclear leucocytes and Staphylococcus aureus in the presence and absence of opsonins. Immunology 1984;

16 Crofton RW, Diesselhoff-den Dulk MC, van Furth R. The origin, kinetics, and characteristics of the Kupffer cells in origin, kinetics, and characteristics of the Kupffer cell
the normal steady state. $J$ Exp Med 1978;148:1-17.

17 Verbrugh HA, van Dijk WC, Peters R, van der Tol ME, Peterson PK, Verhoef J. Staphylococcus aureus opsonization mediated via the classical and alternative complement pathways. A kinetic study using MgEDTA chelated serum and human sera deficient in $\mathrm{IgG}$ and complement factors $\mathrm{C} 1$ and $\mathrm{C} 2$. Immunology 1979;36:391-7.

18 Verhoef J, Peterson PK, Kim Y, Sabath LD, Quie PG. Opsonic requirements for staphylococcal phagocytosis. Heterogeneity among strains. Immunology 1977;33:191-7.

19 Haagen IA, Heezius HC, Verkooyen RP, Verhoef J, Verbrugh HA. Adherence of peritonitis-causing staphylococci to human peritoneal mesothelial cell monolayers. J Infect Dis 1990;161:266-73.

20 Vandenbroucke-Grauls CMJE, Thijssen HMWM, Verhoef J. Phagocytosis of staphylococci by human polymorphonuclear leukocytes is enhanced in the polymorphonuclear leukocytes is enhanced in the

21 Klebanoff SJ, Clark RA. Phagocytosis. In: Klebanoff SJ, Clark RA, eds. The neutrophil. Function and clinical disorders. Amsterdam: North-Holland Publishing Company, 1978:163-216.

22 Glass E, Stewart J, Weir DH. Presence of bacterial binding "lectin-like" receptors on phagocytes. Immunol 1981; 44:529-34.

23 Allison AC, Davies P, de Petris S. Role of contractile microfilaments in macrophage movement and endocytosis. Nature 1971;232:153-5. 